\title{
Small supracilliary incision for the management of fracture of supraorbital rim and anterior wall of frontal sinus
}

\author{
Amit Agrawal \\ Professor of Neurosurgery, Department of Neurosurgery, Narayna Medical College Hospital, \\ Chinthareddypalem, Nellore, Andhra Pradesh (India)
}

\begin{abstract}
With the development of biomedical materials and new techniques in craniofacial sinus surgery, the management of frontal sinus fractures is advanced considerably. We discuss a case of fracture of anterior wall of frontal sinus that was also associated with fracture of the supra-orbital rim and describe supracilliary approach through a small incision (approximately $3 \mathrm{~cm}$ ) used for the management in this case. With this approach we could successfully expose and reduce the fracture fragments without the need for coronal incision, endoscope or intra-operative imaging.
\end{abstract}

Key words: fractures, bone, orbit, frontal, frontal bone, frontal sinus.

\section{Introduction}

An estimated $1 \%$ to $9 \%$ of facial fractures can involve the supraorbital rim and the anterior table of the frontal sinus $(1,2,3)$ resulting in significant ophthalmologic and cosmetic morbidity. (4, 5) With the development of biomedical materials and new techniques in craniofacial sinus surgery the management of frontal sinus fractures is advanced considerably. (4-8) We discuss a case of fracture of anterior wall of frontal sinus associated with fracture of supra-orbital rim and describe supracilliary approach through a small incision (approximately $3 \mathrm{~cm}$ ) used for the management in this case.

\section{Case report}

24 year gentleman presented with approximately 6 hours after the road traffic accident. He had transient loss of consciousness and nasal bleeding. There was no history of vomiting or seizures. His general and systemic examination was normal. There were no neurological deficits. On local examination he had depression on the mid forehead and of the left supra-orbital rim. Extra-ocular movements were full in all directions. Computerized tomography (CT) scan showed depressed fracture of anterior wall of frontal sinus and associated fracture of left supra-orbital rim. There was no evidence of intra-cranial injury, the posterior wall of frontal sinus was intact and there was no blood 
in the sinus (Figure 1). The fractured frontal sinus wall was exposed through a $3 \mathrm{~cm}$ left supracilliary incision (Figures $2 \mathrm{~A}$ and $2 \mathrm{~B}$ ). The edge of the frontal bone lateral to the fractured fragments on left side was drilled to make space to introduce the Penfield's dissector (Figure 2C horizontal arrow). The dissector was introduced through the gap and fractured fragments could be elevated with ease with good alignment (Figure 2C vertical arrow). Patient is doing well at follow up with good cosmetics (Figure 3).

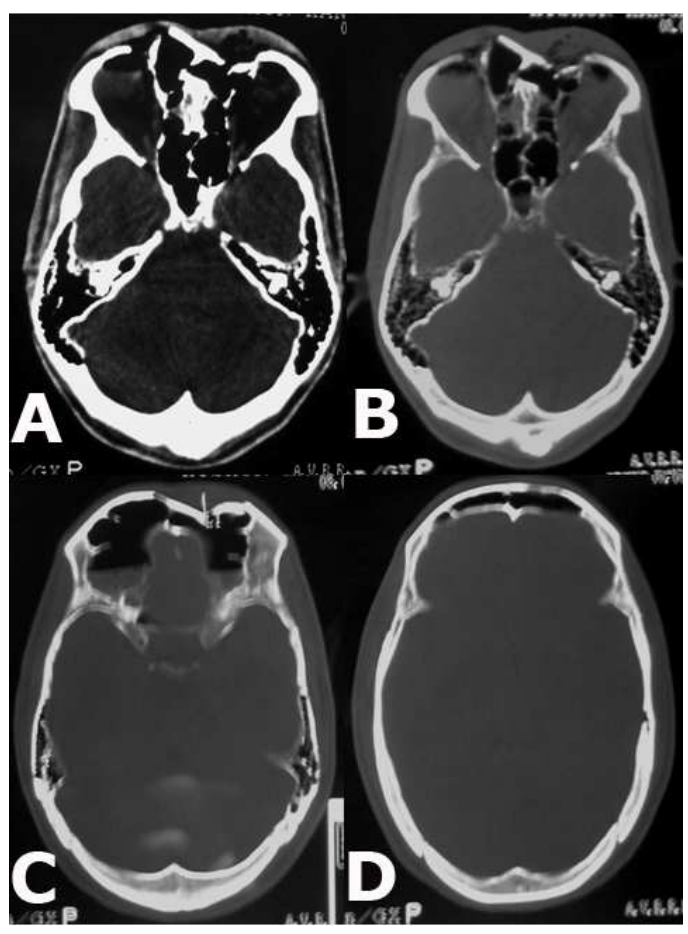

Figure 1 - CT scan showing isolated fracture of anterior table of frontal sinus
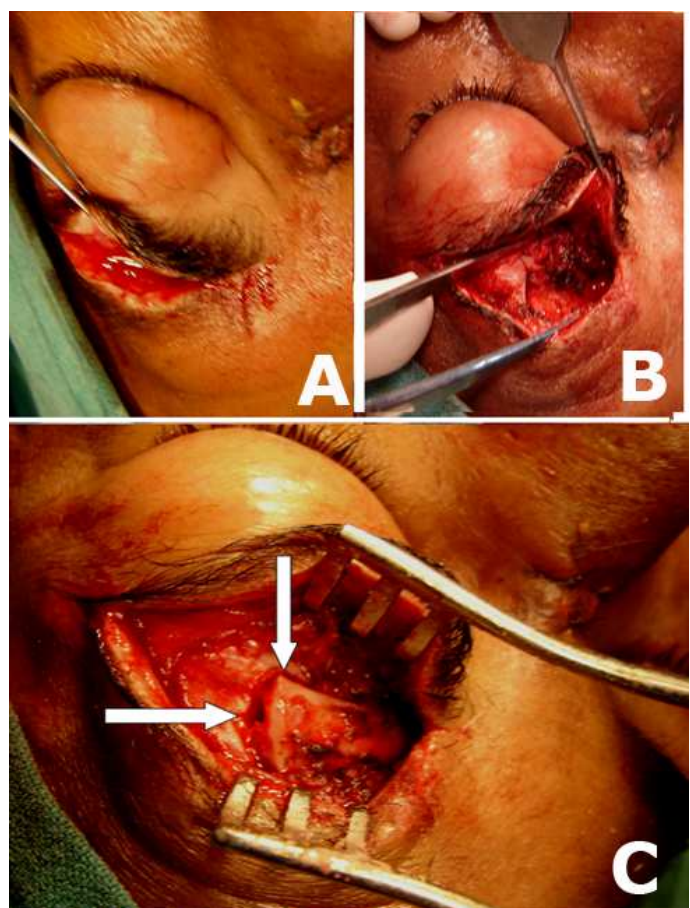

Figure $2-3 \mathrm{~cm}$ supracilliary incision (A), exposure of fractured fragments (B), edge lateral to the fracture was drilled (C, horizontal arrow) and fractured fragments were elevated

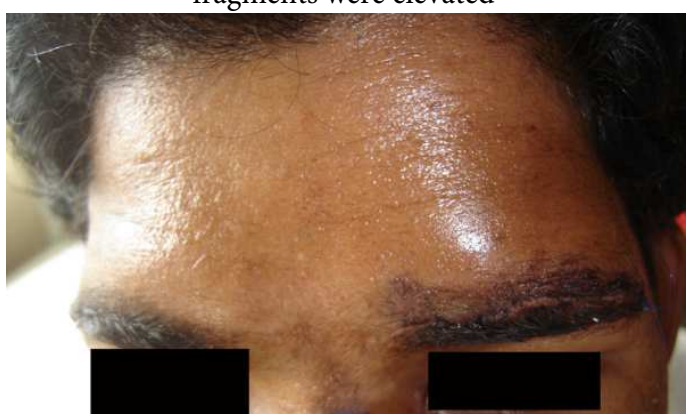

Figure 3 - Post-operative image showing good cosmetic result with least visible scar

\section{Discussion}

The use of high-resolution CT is used for the evaluation of the frontal sinus and it also helps to rule out the damage to the posterior table of the frontal sinus, any associated 
DOI: 10.2478/romneu-2014-0044

intracranial or facial skeleton injuries. (4) Before planning for surgical intervention through small corridor the patency of the frontonasal duct needs to be determined so to avoid delayed but serious infectious complications. $(9,10)$ The treatment of supraorbital rim fractures is indicated for functional and esthetic reasons and it ranges from conservative observation to open reduction and internal fixation of the fracture fragments. (4) A non-displaced supraorbital rim fracture generally requires no surgical intervention and treatment of concomitant neurological or soft tissue injuries may be the only management that is needed. (9) However, as in present case when the fracture segments are displaced, surgical exploration, reduction and stabilization is indicated. (4) Classically, open reduction of isolated anterior table fractures require a bicoronal incision for exposure, reduction, and rigid fixation. $(4,11)$ While the success rates with a coronal incision are very high, the procedure can result in postsurgical stigmata including a large scar, possible alopecia, parasthesias, and, rarely, facial nerve injury. (11) The recent development of instrumentation and techniques for endoscopic brow-lifting has allowed access to anterior table frontal sinus fractures, without the need for a coronal incision. $(7,8,11)$ The potential endoscopic treatment options for anterior table fractures include closed reduction without internal fixation, closed reduction with internal fixation, and fracture camouflage with bone cement. 11 or implant. (8) It is anticipated that the use of endoscopic technique will reduce operating time, surgical morbidity, and cost.
(8) However, the endoscopy is challenging, success rates vary depending on fracture comminution and also it can only be used for moderately displaced fractures (1-5 mm). (11) Recently a case is described where isolated depressed anterior wall fracture of the frontal sinus was treated by closed reduction to avoid coronal incision. (6) Though the method was a less-invasive technique and could be performed without problem in selected cases, however may not be suitable for complex fractures of the frontal sinus. (6) In present case we used approximately $3 \mathrm{~cm}$ incision to expose and reduce the fracture fragments successfully without the need of coronal incision, endoscope or intra-operative imaging. It has been described in the literature that the reduction is often stable once the fragments have been levered into position because of the absence of muscular displacing forces. (12) We used this principle in our case and did not use the internal fixation as the fractured fragments were stable after reduction. Supraorbital rim fractures, although uncommon, must be recognized promptly and can be best managed by an oral and maxillofacial surgeon or other specialist skilled in the management of facial bone fractures. (4)

\author{
Correspondence \\ Dr. Amit Agrawal \\ Professor of Neurosurgery \\ Department of Neurosurgery \\ Narayana Medical College Hospital \\ Chinthareddypalem \\ Nellore-524003 \\ Andhra Pradesh (India) \\ Email-dramitagrawal@gmail.com
}


dramit_in@yahoo.com

Mobile- +91-8096410032

\section{References}

1.Haug RH. Management of the trochlea of the superior oblique muscle in the repair of orbital roof trauma. J Oral Maxillofac Surg 2000; 58(6):602-6.

2.Penfold CN, Lang D, Evans BT. The management of orbital roof fractures. Br J Oral Maxillofac Surg 1992; 30(2):97-103.

3.Sullivan WG. Displaced orbital roof fractures: presentation and treatment. Plast Reconstr Surg 1991; 87(4):657-61.

4.McGuire TP, Gomes PP, Clokie CML, Sándor GKB.. Fractures of the Supraorbital Rim: Principles and Management. J Can Dent Assoc2006; 72(6):537-40.

5.Lakhani RS, Shibuya TY, Mathog RH, Marks SC, Burgio DL, Yoo GH. Titanium Mesh Repair of the Severely Comminuted Frontal Sinus Fracture. Arch Otolaryngol Head Neck Surg. 2001;127:665-669
6.Mavili ME, Canter HI. Closed treatment of frontal sinus fracture with percutaneous screw reduction. J Craniofac Surg. 2007;18(2):415-9.

7.Manolidis S, Hollier LH Jr. Management of frontal sinus fractures. Plast Reconstr Surg. 2007;120(7 Suppl 2):32S$48 \mathrm{~S}$.

8.Kim KK, Mueller R, Huang F, Strong EB. Endoscopic repair of anterior table: frontal sinus fractures with a Medpor implant. Otolaryngol Head Neck Surg. 2007;136(4):568-72.

9.Hirano A, Tsuneda K, Nisimura G. Unusual frontoorbital fractures in chil $\neg$ dren. J Craniomaxillofac Surg 1991; 19(2):81-6.

10.Stanley RB Jr, Becker TS. Injuries of the nasofrontal orifices in frontal sinus fractures. Laryngoscope 1987; 97(6):728-31.

11.Strong EB, Buchalter GM, Moulthrop THM. Endoscopic Repair of Isolated Anterior Table Frontal Sinus Fractures. Arch Facial Plast Surg. 2003;5:514-521 12.Lanigan DT, Stoelinga PJ. Fractures of the supraorbital rim. J Oral Surg 1980; 38(10):764-70. 